\title{
Desenvolvendo uma Experiência Educacional Interativa Usando Recursos de Visualização de Informação e de Computação Móvel como Estímulo à Construção Colaborativa e Continuada de Conhecimento
}

Jorge F. Franco, Irene K. Ficheman, Alexandra C. Alves, Valkiria Venâncio, Roseli de D. Lopes

Laboratório de Sistemas Integráveis - (LSI-USP)

\{jfranco, irene, alexiaca, venâncio, roseli@ lsi.usp.br\}

Sandra R. R. Cruz, Márcia Santiago, Edna O. Teles, Edna M. M. Aquino

$\mathrm{PMSP} / \mathrm{SME}$

masalelu@ig.com.br, san.mar@uol.com.br, oliveiratelles@yahoo.com.br, ednaaquino@ig.com.br

Resumo. Este artigo descreve um trabalho em andamento, relativo à realização de uma experiência educacional de uso de recursos de visualização de informação e computação móvel de baixo custo na educação básica como uma forma de melhorar a qualidade da educação brasileira. A experiência tem contribuído na avaliação e efetividade da aplicação dos aportes visuais e do equipamento no incremento das ações de ensino-aprendizagem, e engajamento dos indivíduos nos processos educativos formais e informais na escola e fora dela. A experiência tem incentivado ações pedagógicas mais interativas, propiciado domínio técnico coletivo de tecnologias digitais, através de visualização de informação, com democratização, desenvolvimento e compartilhamento de conhecimento. A experiência tem dado suporte para de modo colaborativo, melhorar a infra-estrutura técnica de rede sem-fio do ambiente, e de hardware e software do computador móvel de baixo custo.

Palavras chave: computação móvel, desenvolvimento cognitivo, educação continuada, visualização de informação, sistemas eletrônicos interativos

Abstract. This paper describes ongoing work related to the implementation of an educational experience of using information visualization resources and low cost mobile computing in primary education as a form of improving the quality of Brazilian education. The experience has contributed to evaluate the effectiveness of applying the visual resources and the mobile equipment to enhance teaching and learning actions, and to engage individuals in formal and informal learning processes at school and outside. The educational experience has brought about more interactive pedagogical actions, providing collective technical domain of digital technology, through information visualization, with democratization, development and sharing of knowledge. In a collaborative way the experience has given support to improve the school environment wireless network technical infra-structure, as well as hardware and software technical development of the equipment.

Key words: mobile computing, cognitive development, lifelong learning, information visualization, interactive electronic systems 


\section{Introdução, Contexto, Problematização}

Participar do desenvolvimento de uma experiência educativa cujo objetivo é propiciar inclusão social e digital em grande escala em âmbitos nacional e internacional [UCA, 2007; OLPC Brasil, 2007] tem suporte das diversas interações humanas, técnicas e pedagógicas no ambiente escolar desde 2002, tanto quanto entre a comunidade escolar, objeto deste trabalho, e a equipe de pesquisadores diretamente envolvida na implantação inicial desta experiência. As diversas interações educacionais têm propiciado formação técnica e pedagógica, e ações colaborativas de compartilhamento de saberes de educadores e educandos para compreenderem e lidarem conscientemente com possibilidades de acesso a/e uso constante de sistemas eletrônicos interativos relativos às tecnologias da informação e da comunicação (TIC) na resolução de problemas, com uso de técnicas de visualização de informação nas ações pedagógicas de formação acadêmica interna e na expansão de conhecimentos dos estudantes que os compartilham com outros indivíduos para além do espaço escolar conforme figura-1 [Franco et al., 2007].
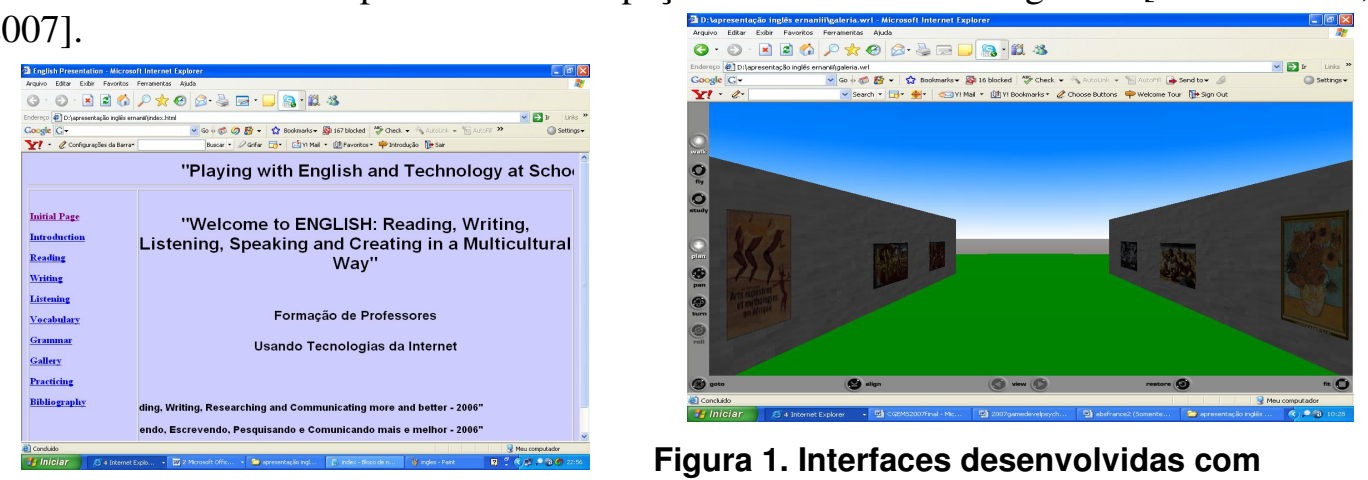

Figura 1. Interfaces desenvolvidas com suporte de tecnologias padrão da Internet (Hypertext Markup Language - HTML e Virtual Reality Modeling Language- VRML) em combinação com arquivos multimídia .wav, .jpg, e .mpg.

As interfaces foram construídas pelo professor Orientador de Informática Educativa - POIE e usadas durante o processo de formação de educadores em horário de estudo coletivo, em outubro de 2006. A oficina interativa foi uma forma de aproximar o conteúdo de uma disciplina (língua inglesa) do processo de comunicação visual, com suporte de tecnologias digitais que circundam os indivíduos em seu cotidiano, e podem ser usadas como recursos para o desenvolvimento cognitivo dos indivíduos, pelas diversas possibilidades de associações entre som e imagem via sistemas eletrônicos como, também, é demonstrado em [Faria, 2005].

Assim, com inspiração em Freire (2004), embasamos de modo reflexivo, em continuidade ao processo de formação dialógica com outros educadores, a possibilidade de uso mais autônomo e adaptabilidade das TIC às diversas disciplinas que compõem a grade curricular, como suporte para melhoria dos processos de ensino e aprendizagem envolvendo leitura, escrita tradicional e digital, contribuindo para minimizar o problema dos elevados índices de alfabetismo funcional que assolam a população brasileira conforme pesquisa [INAF, 2005; IPM, 2005]. Portanto, contribuindo para o desenvolvimento de competências para compreensão, apropriação e uso dos aportes científicos, políticos, tecnológicos, artísticos e culturais pelos indivíduos através de proposição e ação pedagógica integradora capaz de fomentar a qualificação permanente do corpo docente para trabalhar com os distintos conteúdos, tecnologias e diversidade cultural que estão no ambiente escolar. Pode-se, então, pensar em expansão destes 
conhecimentos através da formação dos estudantes, objetivando que sejam cidadãos ativos e críticos, membros solidários de e para uma sociedade com tais características conforme reflexões em [Santomé, 1998]. Tais objetivos podem ser alcançados, com aplicação de estratégias de democratização de conhecimento que elevem o poder de expressividade e comunicação dos cidadãos, com aprendizagem e melhor uso dos recursos tecnológicos e dos sistemas multimídia pela / e através da escola [Masetto, 1997], integrando e fomentando os diversos saberes dos indivíduos via trabalho em equipe, o que amplia as chances de se obter bons resultados educacionais e sociais com as ações pedagógicas [Cialdini, 2007].

\section{Trabalhos Relativos, Bases Pedagógicas e Técnicas}

Nos projetos educacionais NICE [Roussos, 1998], Harnessing Technologies [kelly, 2005], Enquiring Minds (2006) e e-Science Usability (2007), as ações pedagógicas com suporte das TIC em combinação com teorias e metodologias de ensino e aprendizagem, tais como construtivismo, construcionismo, educação experimental e aberta, a zona de desenvolvimento proximal ZPD em [OLPC Brasil, 2007], e o ciclo ganha-ganha de desenvolvimento espiral de software 'Win Win spiral model' conforme [Bohem et al., 1998] citado em [Sharp et al, 2007] embasam a construção de conhecimento de modo colaborativo, interdisciplinar e transdisciplinar.

Similar aos projetos educacionais citados, o uso da combinação entre tecnologia e pedagogia tem contribuído para que, cada vez mais, educadores e educandos se tornem protagonistas em diversos eventos internos e externos, tanto quanto haja aproximação de centros de pesquisas avançadas em educação e tecnologia da escola, como é o caso que acontece no ambiente educacional objeto da experiência em questão.

Por exemplo, em 2004, educadores das áreas de informática, matemática e artes e estudantes foram protagonistas durante oficinas realizadas na III Feira Brasileira de Ciências e Engenharia - FEBRACE, desenvolvendo trabalho interativo com o público durante a feira, em processo de orientação colaborativa de aprendizagem envolvendo uma contadora de histórias, um video disc jockey e uma equipe de pesquisadores universitários. Tecnologias da Internet (HTML e VRML) foram usadas no ambiente da feira para produzir interfaces em 2D e 3D similares ao demonstrado na figura-1, com aplicação de computadores de baixo custo e os avançados sistemas eletrônicos da CAVERNA Digital ${ }^{\mathrm{TM}}$ para desenvolver o script e visualizar o cenário de uma peça relativa à vida e obra de Tarsila do Amaral. Seguindo as influências do trabalho realizado em 2004, durante 2005, educadores das áreas de matemática, geografia, arte, geometria, informática e língua inglesa e seus educandos utilizaram o laboratório de informática da escola para construir trabalho relativo a ampliar os conhecimentos sobre os conceitos de escala, sistema métrico, noção espacial, e desenvolvimento de habilidades comunicativas através de expressão e comunicação visual, textual e oral. Entre outras ações, os indivíduos mediram a escola, construíram a planta baixa, e desenvolveram protótipos tridimensionais 3D de ambientes da escola com suporte das TIC (VRML e HTML), e sistemas de visualização de informação e multimídia de baixo custo, com consequiente apresentação oral e visual para a comunidade escolar, do entorno, autoridades de educação da rede pública, e comunidade acadêmica relativa à educação superior durante visita a uma universidade [Franco et al., 2006; Franco et al., 2007].

O trabalho pedagógico desenvolvido com uso de tecnologias padrão da Internet como ferramentas de autoria têm contribuído para a ampliação das habilidades 
cognitivas gerais e específicas dos educadores e educandos; estimulado a criatividade e o protagonismo juvenil; influenciado na iniciativa para a resolução de problemas das diversas ciências com suporte de sistemas de visualização de informação e computação gráfica [Cunnigham, 2007; Brutzman, 2007]; promovido reflexão e o domínio das inovações tecnológicas como fonte de inspiração e conscientização dos indivíduos sobre a importância de ler e escrever adequadamente, e de responsabilidade com a formação do capital humano e social [Dolabela, 2003] para compreender, usufruir e influir com consciência nos processos de produção de conteúdo tradicional e digital.

As ações educativas têm propiciado condições para o desenvolvimento dos talentos e qualificação das pessoas para interagirem com os novos desafios e constantes mudanças tecnológicas e cientificas do mundo contemporâneo [DUDH, 1948; LDB, 1996], de modo mais autônomo e sustentável em um processo interativo e cooperativo de fomentar crescimento socioeconômico, democratização do acesso ao conhecimento, com apropriação, desenvolvimento e uso das TIC na educação [Vieira 2003; Hippel, 2007; Tapscot e Williams 2007; Balboni 2006].

Os procedimentos e ações educativas realizados servem como suporte para seguir e reforçar a iniciativa de Paulo Freire quando administrou a Secretaria de Educação Municipal de São Paulo - SME (1989 -1992) implantando o Projeto Gênese de Informática Educativa com o objetivo de possibilitar para as classes sócioeconômicas menos favorecidas, acesso aos recursos das TIC para desenvolvimento cultural em [Franco, 2003] citado por [Correia et al., 2007], embasado em processo de formação interativa e continuada de educadores. No decorrer do tempo o Projeto Gênese sofreu modificações. Conforme Decreto $n^{\circ} 34.160$, de 09/05/94 [SINPEEM, 2007] foram implantados mais de trezentos laboratórios de informática nas escolas da rede municipal. Em 1995, devido à necessidade pedagógica de melhor acompanhamento do desenvolvimento individual do aluno no laboratório, através de Portaria posterior, foi criada a função do POIE - Professor Orientador de Informática Educativa, pois tal missão era impossível para um único professor da turma. O papel do POIE era de assessorar o professor da classe durante sua aula no laboratório, havia três horas de estudo na composição da jornada de 25 horas aula, e horários específicos de formação dos professores da unidade escolar nos horários coletivos conforme estabelecido pela (Portaria 303 / 1998) [SINPEEM, 2007].

Em janeiro de 2006, nova portaria de organização do Laboratório de Informática Educativa (Portaria 103) estabeleceu em seu artigo $3^{\circ}$ “(...) $O$ atendimento às classes no Laboratório de Informática Educativa dar-se-á em horários pré e pós-escola, além das 25 (vinte e cinco) horas-aula regulares, de acordo com o Projeto Pedagógico da Escola (...)". Tal mudança influiu para diminuir a qualidade das interações e a formação dos educadores relativa às TIC, desvincular os projetos desenvolvidos pelos alunos no seu horário regular de aula do trabalho no laboratório, dificultou o acesso dos alunos ao laboratório, pois eles deviam retornar a escola em horário alternativo, o que nem sempre acontecia, por motivos de transporte ou falta de acompanhante aos menores, além do que o POIE trabalhava sozinho com os alunos, fato que implicou em dificuldades de acompanhar a evolução da aprendizagem de cada aluno com a devida qualidade. A Portaria 103 foi modificada em agosto de 2006 (Portaria $n^{\circ} 3.669$ ),

“(...) considerando... a necessidade de assegurar que as atividades desenvolvidas no Laboratório de Informática Educativa devem estar integradas no currículo da Escola e considerar a função social no uso das Tecnologias da Informação e da Comunicação, promovendo intercâmbios entre diferentes áreas de conhecimento para resolução de problemas propostos que apresentem relevância social” (...) "O atendimento às classes no Laboratório de Informática Educativa dar-se-á dentro do 
horário regular de aulas dos alunos, de acordo com o Projeto Pedagógico da Escola. (...)"

[SINPEEM, 2007].

Entretanto, na Portaria $n^{\circ} 3669$, o tempo e espaço de formação de professores, para pesquisa e desenvolvimento de projetos diferenciados é reduzido se comparado as possibilidades da Portaria 303/98. Por outro lado, o tempo de formação pode ser ampliado com a implantação de um projeto como o do Um Computador por Criança UCA. Este projeto, com suporte do devido acompanhamento técnico e pedagógico na unidade escolar, pode contribuir para melhorar qualitativamente o sistema educacional e a infra-estrutura, ainda precária da educação brasileira [Saviani, 2000]. Assim, elevar a qualidade do ensino e de cidadania dos indivíduos, que em termos de novas e efetivas oportunidades de desenvolvimento de vida via domínio das TIC, para a maioria dos cidadãos, por enquanto, só acontece através de projetos na escola [Teixeira, 1977].

\section{Implementação e Infra-estrutura}

Os objetivos de implantação e aperfeiçoamento deste projeto englobam influenciar mudança de padrão de pensamento e aos hábitos culturais que estão interligados com as instituições, e segundo Morin, (2002) formam um problema para as reformas, chegandose a uma impossibilidade lógica que forma um duplo bloqueio: "não se pode reformar a instituição sem uma prévia reforma das mentes, mas não se podem reformar as mentes sem uma prévia reforma das instituições” Morin (2002). Por outro lado, o gradativo desenvolvimento de uma infra-estrutura de qualidade para a formação pedagógica e técnica de educadores e educandos tem contribuído para construir nos indivíduos consciência de cidadania necessária para transformar a sociedade [Severino, 1994], e tem propiciado mudança dupla tanto das mentes quanto das instituições envolvidas com respaldo de um processo interativo e colaborativo de construção de uma rede de desenvolvimento social, coletivo e sustentável, com suporte do seguinte pensamento:

\footnotetext{
“(...) A escola pública é por excelência a escola da comunidade, a escola mais sensível a todos os grupos sociais e mais capaz de cooperar para a coesão e integração da comunidade, como um todo. As suas relações com a família não são algo acidental, mas relações intrínsecas, pois, são mais do que tudo, suas representantes em tudo que elas tenham em comum e de mais essencial. A escola pública é o instrumento de integração e da coesão da "grande sociedade", e deve ser o meio de transformá-la na "grande comunidade" (...)" [Teixeira, 1977] .
}

A partir das primeiras notícias veiculadas na mídia em 2005 sobre o projeto One Laptop per Children (OLPC), as bases de desenvolvimento pedagógico e técnico discutidas anteriormente serviram de suporte para as investigações e reflexões iniciais sobre a viabilidade e aceitabilidade do projeto de uso intensivo de computação móvel no cotidiano escolar brasileiro, ainda que, naquele momento a comunidade educacional em questão, não cogitasse fazer parte da experiência. $O$ interesse e a aceitabilidade dos educadores quando perguntados sobre o motivo de ser importante participar do projeto e ter computação móvel em sala de aula, em grande parte das reflexões, foram embasados nas possibilidades de acesso dinâmico a visualização de informação em tempo real e no momento em que fosse necessário por eles e pelos estudantes. No decorrer do ano de 2006, a comunidade escolar participou de reuniões e pesquisas de aceitabilidade de modo informal e formal [Correia et al, 2006]. Em uma dessas reuniões, junho de 2006, o Professor Orientador de Informática Educativa - POIE foi questionado pela comissão de educadores e técnicos credenciados pelo governo federal para acompanhar os estudos iniciais da experiência em questão sobre a condição de formação pedagógica e técnica dos educadores da unidade escolar e se eles estariam aptos a desenvolver algum projeto usando computador sem a presença do POIE. O professor (POIE) respondeu afirmativamente e descreveu, entre outros, os exemplos de projetos colaborativos 
desenvolvidos na unidade escolar, citados na introdução deste artigo como efetivos na formação dos educadores e da consciência desses sobre a importância das TIC para o desenvolvimento de conhecimento. Complementou suas reflexões afirmando que mesmo que os educadores tivessem pouco domínio técnico das linguagens utilizadas na construção dos conteúdos, a compreensão do uso delas e sua utilidade para o desenvolvimento cognitivo e educacional dos alunos tanto quanto a possibilidade de construir projetos educacionais dinâmicos e interativos com participação ativa dos estudantes é que atraíram o engajamento de mais educadores nas propostas de desenvolvimento de projetos e por conseqüência dos estudantes.

Após estudos e reuniões das comissões técnicas e pedagógicas credenciadas pelo governo federal, a comunidade escolar foi convidada a participar da experiência protótipo. Com a aceitação do convite feito à comunidade escolar e parecer favorável unânime do Conselho de Escola (educadores, alunos, pais e equipe técnica) em [O Estado de São Paulo, 2007], iniciou-se o processo de formação dos educadores em setembro de 2006, com interações continuas entre a equipe de pesquisadores de uma universidade, da OLPC e educadores da escola. Foram feitas entrevistas com os educadores durante os períodos de formação coletiva, para que se conhecessem melhor suas expectativas; colher suas sugestões sobre como o projeto poderia ser desenvolvido, identificar quais eram as habilidades que já haviam desenvolvido com relação às TIC.

Em janeiro de 2007, um assessor da presidência da República do Brasil visitou o ambiente escolar e do entorno, confirmando a participação na experiência. A partir de abril, a formação técnica e pedagógica de educadores e estudantes têm sido ampliadas, através de oficinas de formação que dão suporte à experiência educativa (figura-2).
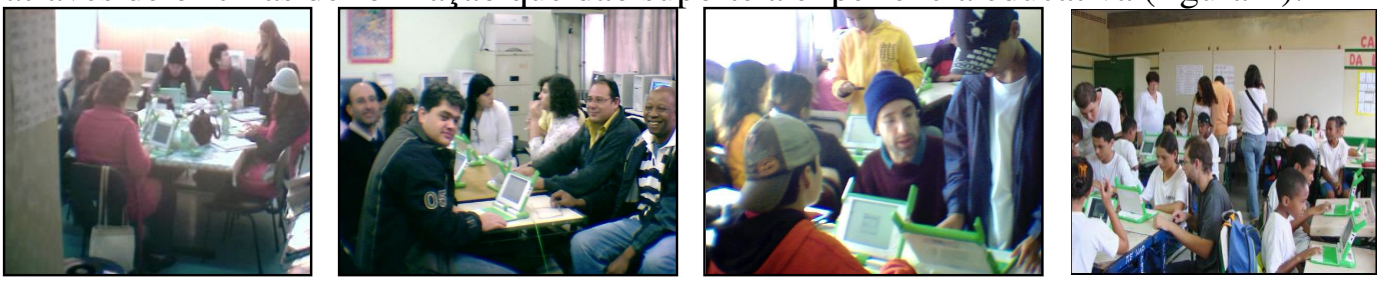

Figura 2. Oficinas de formação - educadores, alunos e pesquisadores do LSI

\section{Casos de Uso}

Após chegada dos laptops, em abril de 2007, foram feitas oficinas com uma educadora do $2^{\circ} \mathrm{C}$ do ensino fundamental I e educadores e educadoras do ensino fundamental II do $5^{\circ} \mathrm{C}$. Os educadores e as classes foram escolhidos em consenso com a coordenação pedagógica da escola, tendo como base interesse dos educadores em participar e fazerem parte de um dos grupos de estudos em horário coletivo. Depois da escolha, foi explicado para as crianças que não iriam participar inicialmente da experiência o processo do trabalho, pois todos/as viam a movimentação, os comentários, e todos/as queriam ter acesso, o que é natural. Após algumas reflexões chegou-se ao consenso que seria importante compartilhar o uso dos equipamentos com os demais educadores e estudantes no decorrer do ano, fato que tem ocorrido, devido ao bom uso dos equipamentos e o reconhecimento pelos mantenedores do projeto que estão enviando mais laptops.

A classe do $2^{\circ}$ ano foi a primeira a usar um conjunto de 35 laptops dos 70 disponíveis para a experiência naquele momento. A experiência foi acompanhada por pesquisadores universitários que contribuíram em parceria com técnicos da Prodam com a logística de implantar a rede sem fio e servidor usado para hospedar Blog interno. Os 
pesquisadores orientaram os estudantes quanto aos programas existentes no laptop, ajudando a refletir sobre seu uso e a atualizá-los. Em 19 de abril, após três dias de interações com o laptop como suporte de desenvolvimento de seqüência didática, a educadora e os estudantes do $2^{\circ} \mathrm{C}$ receberam a visita do pesquisador Nicholas Negroponte conforme vídeo em [Yahoo News, 2007]. Os estudantes interagiram com o pesquisador e equipe mostrando as suas primeiras produções usando os laptops. As produções envolveram pesquisa na Internet e de livros na biblioteca da escola sobre a obra de Monteiro Lobato. Entre outras atividades, os estudantes fizeram pequenos vídeos, tiraram fotos das personagens dos livros, escreveram textos referentes às várias personagens criadas por Monteiro usando o laptop, e inseriram imagens para ilustrá-los.

No $5^{\circ} \mathrm{C}$ os educadores estão usando o laptop para diversos projetos. Os laptops estão sendo usados para pesquisa, visualização de informação, formatação e produção de conteúdo. Na disciplina de ciências com base nos jogos Pan-americanos, foi feito um projeto de nutrição e saúde no primeiro semestre e no segundo semestre está em andamento o projeto sobre poluição. Na disciplina de matemática a educadora aproveitou o tema Pan-americano para desenvolver entendimento sobre como construir e ler gráficos. Em história: durante o pan-americano, os alunos pesquisaram sobre os diversos aspectos econômicos dos países participantes. Atualmente tem sido feito pesquisas sobre a pré-história: períodos paleolítico, neolítico e idade dos metais. Os alunos visualizam a linha do tempo e procuram por informações solicitadas pelo educador na Wikipedia. O projeto tem a finalidade de contribuir para que os alunos/as aprendam sobre metodologia de pesquisa e organização de texto figura-3.
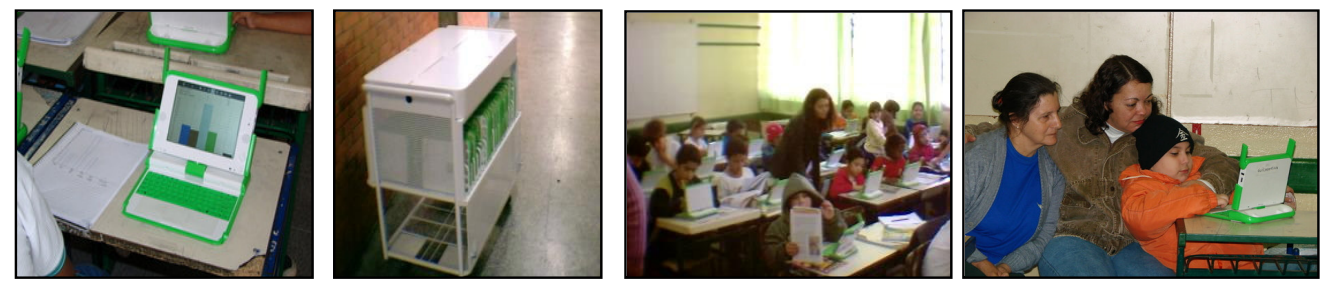

Figura 3. Visualização de Informação, carrinho dos laptops, interação de uma educadora com alunos, e aluno com responsáveis durante reunião

Em maio aconteceu reunião com pais/mães/responsáveis. Foi apresentado o projeto a toda a comunidade escolar e houve conversa com os mesmos a respeito da possibilidade de levar os laptops para casa. A maioria dos pais foi favorável à idéia, dando inclusive sugestões de como poderia ser a organização: disseram que a escola poderia avisar com antecedência e eles se organizariam para virem buscar as crianças nesse dia e trazê-las na data de entrega dos laptops, assim não andariam sozinhos/as na rua com o equipamento para evitar roubos, entre outros problemas.

Os alunos e alunas do $2^{\circ}$ ano $\mathrm{C}$ tanto quanto três monitores da sala, mediante autorização e suporte de seus responsáveis, levaram os laptops para casa no último final de semana do mês setembro. Os laptops serviram como objetos de aprendizagem em [Dutra e Tarouco, 2006] e de estímulo às interações sociais entre os educandos e seus responsáveis com produção de fotos, vídeos e oportunidades de alfabetização digital conduzida pelas crianças em seus lares. Após o retorno dos laptops, a professora do $2^{\circ}$ ano $\mathrm{C}$ usou o material produzido durante as interações familiares para construir texto coletivo com as crianças. Ela, também, organizou rodas de comunicação, nas quais os alunos(as) expressaram o que fizeram usando o laptop durante o final de semana. 
Além das interações descritas, a experiência educativa tem propiciado contato da comunidade com vários mantenedores do projeto UCA, fato que tem influído na melhoria a auto-estima dos educadores e educandos. Em junho, visitaram a escola um assessor da presidência, deputados federais, do Banco Interamericano de Desenvolvimento representantes da OLPC, e da AMD South América; em Julho a comissão de pedagogos e técnicos designados pelo governo federal para avaliar a experiência; e em agosto visita de pesquisadores do MIT. Em suma, após conversarem com os educadores e alunos da comunidade escolar mostraram-se satisfeitos com as ações realizadas, e têm disponibilizado mais laptops em quantidade suficiente para serem compartilhados por todos os educadores e alunos, tanto quanto materiais didáticos diferenciados para serem avaliados. Estas interações internas, tanto quanto visitas culturais monitoradas, como foi a ida ao Itaú Cultural (2007) em 2 de agosto, para visitar a Exposição Memória do Futuro. Nesta visita, 45 estudantes levaram os laptops e registraram em tempo real suas impressões. Alguns dos estudantes observaram que os ambientes virtuais lá expostos tinham configuração similar aos materiais virtuais produzidos por eles ou seus pares usando VRML conforme descrito no inicio do artigo.

\section{Resultados Parciais e Conclusões}

As dificuldades estruturais, materiais e burocráticas inicialmente encontradas foram solucionadas. As relativas ao uso das máquinas no dia-a-dia do trabalho são resolvidas com o coletivo - "para minha satisfação, as dificuldades previstas não foram, nem de longe, obstáculos, foram dificuldades que, discutidas e adaptadas às necessidades do projeto, foram facilmente transpostos. (...) Desenvolvi a idéia do projeto sobre ONG para aplicação deste com minha $\sigma^{a}$ série justamente por ter a oportunidade $e$ possibilidade de ter um instrumento de acesso tão atraente e eficaz que são os laptop (...)Os alunos mostram-se agora mais atentos às aulas convencionais, não ficam ansiosos e na expectativa de a todo momento trabalhar com os computadores e percebi que a cumplicidade e o retorno de outros trabalhos têm aumentado"(Depoimento da professora Flávia A. Reigota).

Conforme o depoimento supra, a aceitação da experiência é grande, implicando em diminuição nas faltas dos alunos. Os aluno(as) do $1^{\circ}$ ao $8^{\circ}$ e da Educação de Jovens e Adultos EJA têm tido acesso aos equipamentos. $\mathrm{O}$ acesso tem sido expandido pelo suporte que os professores têm dado uns aos outros e recebido dos pesquisadores do LSI. Também, pelo suporte técnico durante as aulas de alunos monitores que têm se engajado e revezado no sentido de organizar o material disponível. Os monitores têm prestado serviços de ajuda técnica aos estudantes de todas as séries. Entretanto, a ajuda de dois a três monitores nas salas de $1^{\circ}, 2^{\circ}$ e $3^{\circ}$ anos têm sido fundamental para que os professores(as) façam a condução pedagógica com mais efetividade enquanto vão aprendendo a dominar os conceitos técnicos. A infra-estrutura de rede sem fio tem sido melhorada para que no futuro sejam feitas experiências dos alunos levarem os laptops para casa nos finais de semana e também tenham acesso a Internet. A idéia é aproximar o ambiente da escola do ambiente familiar pelo conhecimento. Os alunos/alunas têm dito que ficou mais fácil pesquisar e visualizar as orientações dos professores, tanto quanto produzir os projetos educativos e espera-se que num futuro próximo estes conceitos sejam compartilhados em seus lares [SPTV Globo, 2007; JORNAL HOJE Globo, 2007).

As conclusões são preliminares, uma vez que o processo de implantação é recente, e o fato de ser novidade, por si só, é motivador, mas o entusiasmo só 
permanecerá se as atividades forem significativas para estudantes e professores. A tendência é que as próximas versões do laptop propiciem interações com softwares com a velocidade e qualidade próximas às oferecidas no laboratório da escola. Assim, será possível, cada vez mais, contribuir para formar cidadãos ativos e críticos, membros solidários de e para uma sociedade que efetivamente vivencie tais características. É possível alcançar tais objetivos desde a infância, através de formação continuada qualitativa de todos os educadores e educandos para que desenvolvam habilidades para lidar com as inovações conforme entrevista de Lea Fagundes em [Midiativa, 2006].

\section{Agradecimentos}

Agradecemos a todos que têm contribuído para o desenvolvimento do trabalho. Deus os abençoe.

\section{Referências}

BALBONI, M., Apresentação. In: Vieira, A. C. G. (org), CGIbr. Pesquisa sobre o uso das tecnologias da informação e da comunicação no Brasil - TIC domicílios - TIC empresas, 2006, http://www.cetic.br/tic/2006/indicadores2006.pdf Acessado: 08 ago. 2007

CIALDINI, R. B., (2007). Como tirar o máximo rendimento do trabalho em equipe, em: LIMA, P., (Editor) RevistaGol, executiva-havardnews, julho 2007, Brasil, ThipEd.pp. 104-105.

CORRÊA, A. G. D., ASSIS, G., FICHEMAN, I., VENÂNCIO, V. e Lopes, R., 2006. Avaliação de Aceitabilidade de um Computador Portátil de Baixo Custo por Criança, em Anais Digital, XVII Simpósio Brasileiro de Informática na Educação - SBIE, 8 a 10 de novembro de 2006, Brasília.

CUNNIGHAM, S., (2007) Programming in OpenGL for visual communication, Pearson Prentice Hall, USA, pp. 331-395.

DOLABELA, F., (2003). PedagogiaEmpreendedora, Brasil,EditoradeCultura, pp.47-51,91-93.

DUDH - Declaração Universal dos Direitos Humanos (1948) http://www.unhchr.ch/udhr/lang/por.htm

DUTRA, R. L. S. e TAROUCO, L. M. R. Objetos de aprendizagem: uma comparação entre SCORM e IMS Learning Design, RENOTE - Revista Novas Tecnologias na Educação, VII Ciclo de Palestras Novas Tecnologias na Educação, 2006 Vol. $4 \mathrm{~N}^{\circ} 1$ http://www.cinted.ufrgs.br/renote/jul2006/artigosrenote/a1_20138.pdf Acesso em: 14 out. 2007

DYER, S., MARTIN, J. and ZULAUF, J. (1995) "Motion Capture White Paper", http://reality.sgi.com/employeesjam_sb/mocap/MoCapWP_v2.0.html,December.Acessado:08ago. 2007

ENQUIRING Minds, (2006) Young people as researchers on enquiring minds, http://www.enquiringminds.org.uk/findings/reports and_papers/young researchers/index.html Ago. 2007

ESTADO, O Estado de São Paulo, (2007). Um passeio cultural com laptop a tiracolo; Excursão testa potencial pedagógico - Sexta - 3/8/2007 http://www.estado.com.br/editorias/2007/08/03/ger-1.93.7.20070803.4.1.xml

FARIA, R. R. A., Auralização em Ambientes Audiovisuais Imersivos, Tese_Rev http://www.lsi.usp.br/\%7Eregis/FariaRRA AuralizacaoAmbientesImersivos Tese Rev web.pdf

FRANCO, J. F., LOPES, R. D., Novas Tecnologias em Ambientes de Aprendizagem; Estimulando o Aprender a Aprender, Transformando o Currículo e Ações. III Ciclo de Palestras sobre Novas Tecnologias na Educação, 2004. http://www.cinted.ufrgs.br/ciclo3/af/39-novastecnologias.pdf

FRANCO, J. F.; CRUZ, S. R. R.; LOPES R. D., Computer Graphics, Interactive Technologies and Collaborative Learning Synergy Supporting Individuals' Skills Development, The 33 International Conference And Exhibition on Computer Graphics and Interactive Techniques, SIGGRAPH 2006, 30 July - 03 August 2006, Educators Program, Boston Convention and Exhibition Center - Boston Massachusetts - USA http://delivery.acm.org/10.1145/1180000/1179338/p42franco.pdf?key $1=1179338 \&$ key2 $=0205817711 \&$ coll $=\& \mathrm{dl}=\mathrm{ACM} \& \mathrm{CFID}=15151515 \& \mathrm{CFTOKEN}=6184618 \mathrm{G}$

FRANCO, J. F.; FRANCO, N.F.; LOPES, R. D.; CRUZ, S. R. R. Experiências de Uso de Mídias Interativas como Suporte para Autoria e Construção Colaborativa do Conhecimento, RENOTE - Revista Novas Tecnologias na Educação, IX Ciclo de Palestras Novas Tecnologias na Educação, 16 a 18 de julho de 2007a http://www.cinted.ufrgs.br/ciclo9/artigos/2cJorge.pdf

HERNÁNDEZ, F., (2000). Cultura visual, mudança educativa e projeto de trabalho, Porto Alegre, ARTMED, 2000, pp. 50-51.

HIPPEL, E. V., Democratizing innovation, USA, The MIT Press, 2006.

INAF, $5^{\circ}$ Indicador Nacional de Alfabetismo Funcional, (2005). Um Diagnóstico para Inclusão Social pela Educação, http://www.acaoeducativa.org.br/downloads/inaf05.pdf

IPM - Instituto Paulo Montenegro, (2005), Vídeo Alfabetismo Funcional, http://www.ipm.org.br/ipmb pagina.php?mpg=4.98.00.00.00\&c id audvid=32\&acesso=modem\&ver=por

Itaú Cultural, (2007). http://www.itaucultural.org.br/index.cfm?cd_pagina=2688

JORNAL HOJE Globo, (2007), http://video.globo.com/Videos/Player/Noticias/0, ,GIM736353-7823INFORMATICA+UMA+ALIADA+DA+EDUCACAO,00.html Acesso em : 23 out. 2007 
KELLY, R., (2005). Harnessing Technologies : Transforming Learning and Children's Services, http://www.dfes.gov.uk/publications/e-strategy/docs/e-strategy.pdf

KELLY, S., Sung, C., \& Farnham S. (2002). Designing for Improved Social Responsibility and Content in On-Line Communities. In Proceedings of CHI 2002, Minneapolis, April 2002. http://research.microsoft.com/scg/papers/DesigningforCommunity.pdf

LDB, Lei Brasileira de Diretrizes e Bases da Educação Nacional, (1996) http://64.233.167.104/search?q=cache:KewSWvH4imMJ:portal.mec.gov.br/arquivos/pdf/ldb.pdf+ldb\&hl=ptBR\&ct=clnk\&cd=1\&gl=br Acessado: 10 ago. 2007

MASETTO, M., (1997). Didática: A aula como centro, Brasil FTD, pp. 95-97.

MIDIATIVA, (2006) Léa Fagundes: "O professor deve tornar-se um construtor de inovações", http://www.midiativa.tv/index.php/educadores/content/view/full/1053

MORIN, E., (2002). A cabeça bem-feita: repensar a reforma - reformar o pensamento, Brasil, Bertrand Brasil, $7^{\circ}$ edição, pp. 99 - 104.

OLPC Brasil, (2007) http://wiki.laptop.org/go/OLPC_Brazil Acessado: 08 ago. 2007

ROUSSOS, M.; JOHNSON, A. E.; LEIGH, J.; Barnes, C. R.; VASILAKIS, C. A. e MOEHR, T. G., (1999) Learning and building together in an Immersive virtual world. In Presence vol. 8, n. 3, June 1999, pp. 247 - 263. http://www.evl.uic.edu/aej/vrais98/vrais98.2.html

SANTOMÉ, J. T., (1998). Globalização e Interdisciplinaridade: O currículo integrado, Brasil, Artmed, pp. 95-147.

SAVIANI, D., (2000). Educação Brasileira, Estrutura e Sistema, Brasil, Editora Autores Associados, $6^{\circ}$ edição, pp. 109-120.

SHARP, H.; ROGERS, Y. e PREECE, J., (2007) Interaction design: beyond human-computer interaction, 2nd edition, USA, John Wiley\& Sons, Ltd.,pp. 17,240-287,448-451.

SINPEEM,(2007) http://www.sinpeem.com.br/lermais materias.php?cd materias=306

SMITH, H.; Fitzpatrick, G. e Good, J., (2007). E-Science Usability, http://www.informatics.sussex.ac.uk/research/groups/interact/escience-usability.htm

SPTV Globo, Educação aliada à tecnologia: alunos da periferia testam lap-tops, (2007) http://video.globo.com/Videos/Player/Noticias/0,,GIM717992-7823-

ALUNOS+DA+PERIFERIA+TESTAM+LAPTOPS, $00 . \mathrm{html}$

TAPSCOTT, D. e WILLIAMS, A. D., Wikinomics: how mass collaboration changes everything, USA, Portifólio, 2007

TEIXEIRA, A., (1977). Educaçãonãoéprivilégio, Brasil, Atualidades pedagógicas, pp. 162-219.

THOMAS KUNZ, J. P. BLACK, An Architecture for Adaptive Mobile Applications In Wireless '99. Calgary, Canada (1999) http://big.uwaterloo.ca/publications/pdfs/conf25.pdf

UCA, (2007) http://pilotosdoprojetouca.blogspot.com/2007 $01 \quad 01$ archive.html

VIEIRA, A. T., Sistemas de informação e comunicação: apoio à aprendizagem coletiva na escola. In: VIEIRA, A. T.; ALMEIDA, M. E. B. e ALONSO, M., Gestão educacional e tecnologia, Brasil, AVERCAMP Ed., 2003, 131-150 p.

Yahoo News, (2007). http://60minutes.yahoo.com/segment/69/one_laptop_per_child 